Article

\title{
An Adaptive Control Scheme for Variable Speed Wind Turbines Providing Frequency Regulation in Isolated Power Systems with Thermal Generation
}

\author{
Ana Fernández-Guillamón ${ }^{1,+}$ [D , Guillermo Martínez-Lucas ${ }^{2, *,+}$ (D) and Ángel Molina-García ${ }^{1,+}$ \\ and Jose Ignacio Sarasua $2,+$ (D) \\ 1 Department of Automatics, Electrical Engineering and Electronic Technology, Universidad Politécnica \\ de Cartagena, 30202 Cartagena, Spain; ana.fernandez@upct.es (A.F.-G.); angel.molina@upct.es (Á.M.-G.) \\ 2 Department of Hydraulic, Energy and Environmental Engineering, Universidad Politécnica de Madrid, \\ 28040 Madrid, Spain; joseignacio.sarasua@upm.es \\ * Correspondence: guillermo.martinez@upm.es; Tel.: +34-91-067-43-33 \\ + These authors contributed equally to this work.
}

Received: 27 May 2020; Accepted: 28 June 2020; Published: 1 July 2020

\begin{abstract}
The lack of synchronous inertia, associated with the relevant penetration of variable speed wind turbines (VSWTs) into isolated power systems, has increased their vulnerability to strong frequency deviations. In fact, the activation of load shedding schemes is a common practice when an incident occurs, i.e., the outage of a conventional unit. Under this framework, wind power plants should actively contribute to frequency stability and grid reliability. However, the contribution of VSWTs to frequency regulation involves several drawbacks related to their efficiency and equipment wear due to electrical power requirements, rotational speed changes, and subsequently, shaft torque oscillations. As a result, wind energy producers are not usually willing to offer such frequency regulation. In this paper, a new control technique is proposed to optimize the frequency response of wind power plants after a power imbalanced situation. The proposed frequency controller depends on different power system parameters through a linear regression to determine the contribution of wind power plants for each imbalance condition. As a consequence, VSWTs frequency contribution is estimated to minimize their mechanical and electrical efforts, thus reducing their equipment wear. A group of sixty supply-side and imbalance scenarios are simulated and analyzed. Results of the case study are compared to previous proposals. The proposed adaptive control reduces the maximum torque and rotational speed variations while at the same time maintaining similar values of the load shedding program. Extensive results and discussion are included in the paper.
\end{abstract}

Keywords: frequency control; isolated system; linear regression; power system stability; wind turbines

\section{Introduction}

The different services carried out by the transmission system operators (TSO) for a reliable and secure power system are known as ancillary services [1]. Among them, load-frequency control focuses on mitigating the effects of unpredictable changes both in the demand and in the generation units that can address frequency deviations [2]. In fact, power imbalances between generation and consumption cause frequency variations [3]. In Europe, frequency control has a hierarchical structure, usually organized in up to five layers (from fast to slow timescales): (i) frequency containment (also known as primary frequency control); (ii) imbalance netting; (iii) automatic and/or manual frequency restoration (also known as secondary frequency control), and (iv) replacement [4]. If the different reserves of such frequency control layers are consumed or unable to keep frequency within an acceptable range, a variety of strategies called special protection systems are then used. Load shedding 
is included in those special protection systems. Moreover, it is considered as the last option to prevent frequency instability [5]. Despite load shedding being an effective solution to prevent a power system collapse after a major imbalance, it is considered as an undesirable situation and it is important to reduce it as much as possible [6-8].

Traditionally, power systems have been based on conventional power plants with synchronous generators directly connected to the grid, automatically providing their stored kinetic energy after a generation-load mismatch [9]. However, in recent decades, power systems have been suffering a slow change from conventional synchronous power plants to inverter-interfaced renewable energy sources (II-RES), i.e., wind power plants based on variable speed wind turbines (VSWTs) and/or solar photovoltaic (PV) [10]. Among them, VSWTs are considered as the most efficient, developed, and installed renewable resource, and currently they account for more than $650 \mathrm{GW}$ of installed capacity around the world [11,12]. This remarkable integration of wind power plants requires an important reformulation of their contribution to ancillary services [13]. Moreover, as they are connected to the grid through power inverters, the synchronous inertia of the power system decreases when such renewable source replaces conventional power plants [14]. Indeed, faster rate of change of frequency (RoCoF) and larger frequency deviations are related to low synchronous system inertia values [15]. These effects are even more critical in isolated power systems [16,17]. As a result, Toulabi et al. consider that, due to the massive integration of VSWTs, their participation into frequency control is necessary [18]. With this aim, different frequency control approaches can be found in the specific literature to effectively replace conventional power plants by VSWTs and maintain a reliable power system operation [19]. These strategies are summarized in Figure 1 according to the different approaches [20,21].

$$
\text { VSWTs frequency control strategies }\left\{\begin{array}{l}
\text { De-loading }\left\{\begin{array}{l}
\text { Over-speed } \\
\text { Pitch angle }
\end{array}\right. \\
\text { Inertia response }\left\{\begin{array}{l}
\text { Droop } \\
\text { Hidden inertia emulation } \\
\text { Fast power reserve }
\end{array}\right.
\end{array}\right.
$$

Figure 1. General classification for Variable Speed Wind Turbines (VSWTs) frequency control techniques.

VSWTs are designed to work in their maximum power point (MPP) according to the available wind speed $s_{w}: p_{M P P}\left(s_{w}\right)$ [22]. As a consequence, the first approach (deloading technique) consists of operating the VSWTs in a suboptimal power point $p_{d e l}$, below $p_{M P P}\left(s_{w}\right)$. Therefore, a certain amount of power $\Delta p_{d}$ can be supplied in case of a power imbalance [23,24]. Two different possibilities are identified [25]: (i) the pitch-angle control and (ii) over-speed control. In the first one, the pitch angle is increased from $\beta_{0}$ to $\beta_{1}$ for a constant $s_{w}$. Subsequently, the generated power $p_{\text {del }}$ is below the maximum power $p_{M P P}$ [26-29]. When the additional power $\Delta p_{d}$ is supplied, the pitch angle reduces to $\beta_{0}$. The over-speed control increases the rotational speed of the rotor, shifting the supplied power $p_{d e l}$ towards the right of the maximum power $p_{M P P}$ [30-32]. When the additional power $\Delta p_{d}$ is supplied, the rotor speed has to be reduced to $\omega_{M P P}$, releasing kinetic energy [33]. However, despite the fact that this technique can improve the long term frequency regulation, it is not an economically viable solution for wind power plants' operators due to loss of profits [34].

Due to the power inverter, VSWTs cannot naturally provide the kinetic energy stored in their rotor and generator. To overcome this, one or more additional control loops must be included in the power inverter. Three different possibilities can be found in the specific literature: (i) the droop control, (ii) the hidden inertia emulation control, and (iii) the fast power reserve approach. The droop control provides an additional active power $\Delta p$ proportional to the frequency deviation $\Delta f$, following $\Delta p=-\frac{\Delta f}{R_{W T}}$, where $R_{W T}$ is the droop control setting of the VSWT [35-39]. This definition of $\Delta p$ gives an adaptive response depending on the frequency excursion severity and thus emulating primary 
frequency control of conventional generation units [40]. The hidden inertia emulation control usually includes two different loops: one considering the RoCoF and the other considering the frequency excursion $(\Delta p \propto \operatorname{RoCoF} \& \Delta f)$ [41-43]. However, there are also proposals to use only one additional loop, being $\Delta p \propto \operatorname{RoCoF}$ [44-46]. Even though these methods improved the nadir frequency (minimum value), a little frequency dip was observed in later stages. This was due to a small reduction in the generated power compared to the prefault active power (thus, not operating in the MPP) [47]. The fast power reserve approach defines the overproduction power $\Delta p$ as a constant value independent of the power system configuration and frequency deviation [48-51] or as a variable value depending on the frequency deviation or minimum rotor speed limits [52-54]. With these three techniques, as the additional power $\Delta p$ is provided, the rotor and generator rotational speeds decrease (subsequently, modifying their torques). Rotor speed variations cause large amplitude edgewise vibrations for the blades [55], affecting the productivity and reducing the efficiency [56]. Large torque increases can address severe mechanical loads on the turbine, even causing critical situations under high mechanical stress conditions [57]. Moreover, consecutive torque increments is related to random load cycles, with important influences on fatigue loads [58].

In this work, a new fast power reserve controller for frequency regulation is proposed for isolated power systems including conventional generation (thermal units) and wind power plants (VSWTs). The proposed adaptive frequency controller is based on a linear regression from different power system parameters (i.e., RoCoF, active power supplied by each synchronous group, and synchronous inertia) to estimate the additional power provided by the wind power plants by maintaining certain frequency thresholds. This way mechanical stress is reduced without excessively prejudicing power system. Subsequently, VSWTs do not always participate in the frequency control but only when they are required according to both the monitored variables. VSWTs frequency control contributions are thus optimized, improving the grid frequency response and providing similar or lower load shedding actions in line with previous frequency control strategies. This proposed VSWT controller approach is tested in the Gran Canaria Island (Canarian archipelago, Spain), an isolated power system where the wind power capacity has doubled since 2017 (from 90 to 180 MW) [59]. Moreover, from 2005 to 2010, more than 200 trips of generators were registered per year in the Canarian archipelago, hence activating the corresponding load shedding programs [60].

The rest of the paper is organized as follows: Section 2 describes the mathematical model used to simulate the power system under consideration; the new frequency control approach proposed in this work is explained in Section 3; cases of study and simulation results are provided in Section 4; Finally, Section 5 gives the conclusions.

\section{Power System Modeling}

A mathematical model has been designed to analyze the proposed VSWT adaptive frequency control in an isolated power system. A generic wind-thermal isolated system is considered in this study (refer to Figure 2), including steam, diesel, gas, and combined cycle units, as well as wind power plants. Consequently, the model developed in Matlab/Simulink (2016) includes these thermal units, one equivalent VSWT acting as the wind power plants, the automatic generation control (AGC), the power system, and the power demand (including a load shedding scheme). The electromagnetic transients are supposed to be much faster than the other components of the model, and their influence in the system's dynamics is omitted [61]. In Figure 3, the block diagram of the power system under study can be seen. 


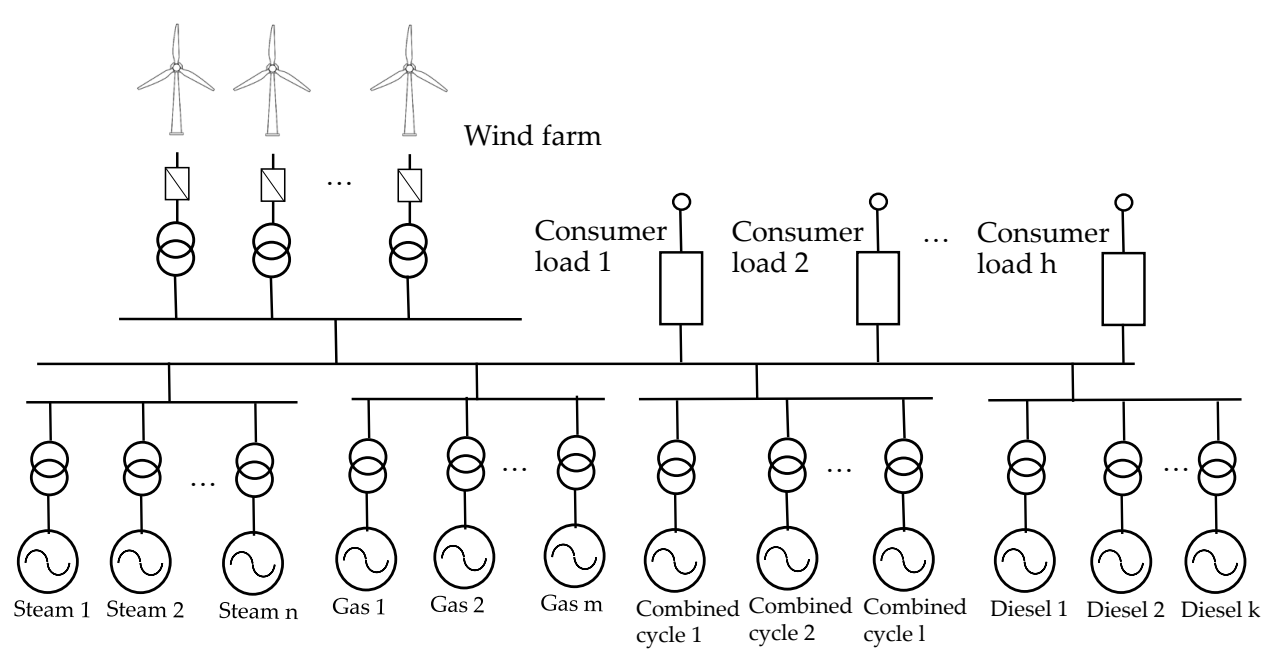

Figure 2. Simplified one-line diagram of the generic isolated power system.

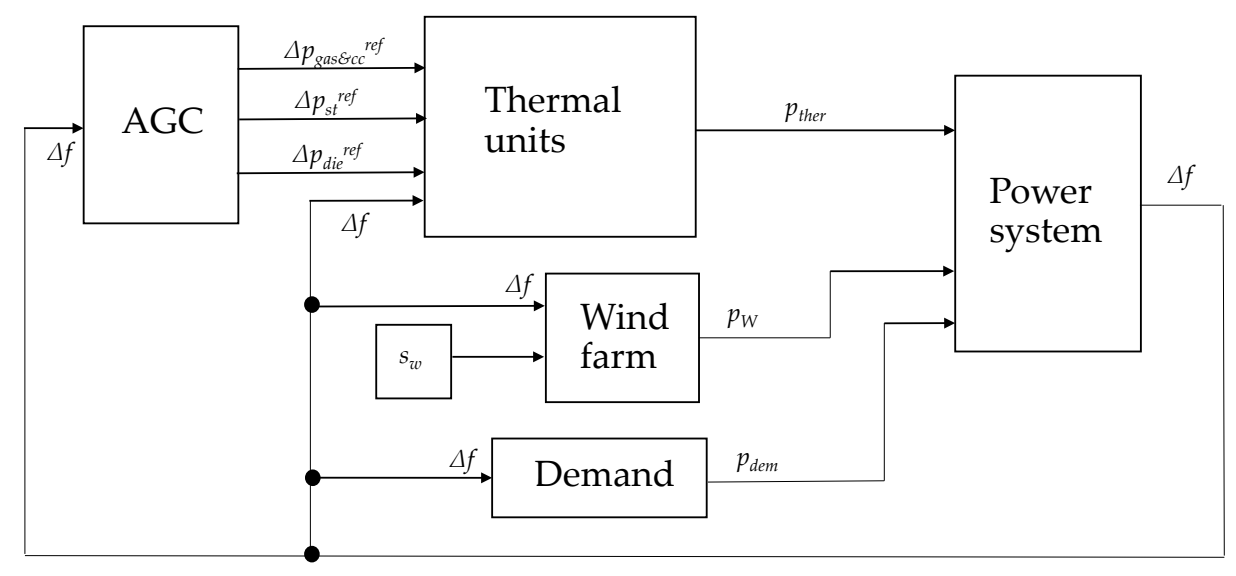

Figure 3. Block diagram of the frequency analysis model.

\subsection{Power System}

Frequency regulation based on droop speed control can be divided into two consecutive control actions: frequency containment and frequency restoration. On the one hand, frequency containment (or primary frequency regulation), which is based on the governor control, adjusts the active power of the generation units to correct frequency variations. In fact, the frequency nadir is directly related with the generator's droop characteristic. In Spanish electric power system, primary regulation services act up to $30 \mathrm{~s}$ after a frequency disturbance [62]. On the other hand, frequency restoration (or secondary frequency regulation) refers to the AGC, adjusting the active power output of generation units to bring system frequency back to its rated value after the governor-based primary response.

An aggregated inertial model is commonly used to analyze frequency deviations in isolated power systems [63]. This modeling approach has been previously applied in El Hierro isolated power system (another isle of the Canarian archipelago) in [64]. Therefore, frequency deviations are the result of the imbalance between the power supplied by the generation units and the power demand:

$$
f \frac{d f}{d t}=\frac{1}{T_{m, t h e r}(t)}\left(p_{\text {ther }}+p_{w}-p_{\text {dem }}-D_{\text {net }} \Delta f\right),
$$

where $T_{m, t h e r}(t)$ corresponds to the total mechanical inertia of thermal units depending on the number of generation operating units at each moment. Note that only thermal units provide inertia to the power system, since VSWTs are decoupled from the grid through power inverters. 
When frequency disturbances are higher than certain limits, an under frequency load shedding scheme is activated to recover the grid frequency and fulfill certain frequency range requirements. In this work, a realistic load shedding scheme is included, consisting of the sequential and sudden disconnection of certain amount of load as established frequency thresholds are exceeded. The load shedding program can be found in [59].

\subsection{Thermal Power Plants}

The different thermal generation technologies (i.e., steam, diesel, gas, and combined cycle) included in the isolated power system are modeled by different transfer functions proposed in $[59,65]$. These transfer functions supply the power variation of each thermal technology from the frequency deviation and power reference provided by the AGC. Both the model and the parameters can be found in [59]. Since fast response of combined cycle power plants is in charge of the gas turbines, frequency response of combined cycle and gas units is assumed to be equal. The total thermal generation is then the sum of each thermal unit power supplied.

\subsection{Variable Speed Wind Turbines}

One equivalent VSWT model aggregating all the VSWTs is used $[59,66]$. The proposed VSWT equivalent model includes the wind power model and both pitch and torque maximum power point tracking control. Further information can be found in [67]. The one-mass rotor mechanical model is used for simulations, which is detailed enough according to [68] for power converters decoupling the generator from the grid. The VSWT diagram is represented in Figure 4. This wind turbine model has been previously used in [69] for short-time period frequency analysis. The equivalent aggregated wind turbine modeling also includes the frequency control response strategy, described in Section 3.

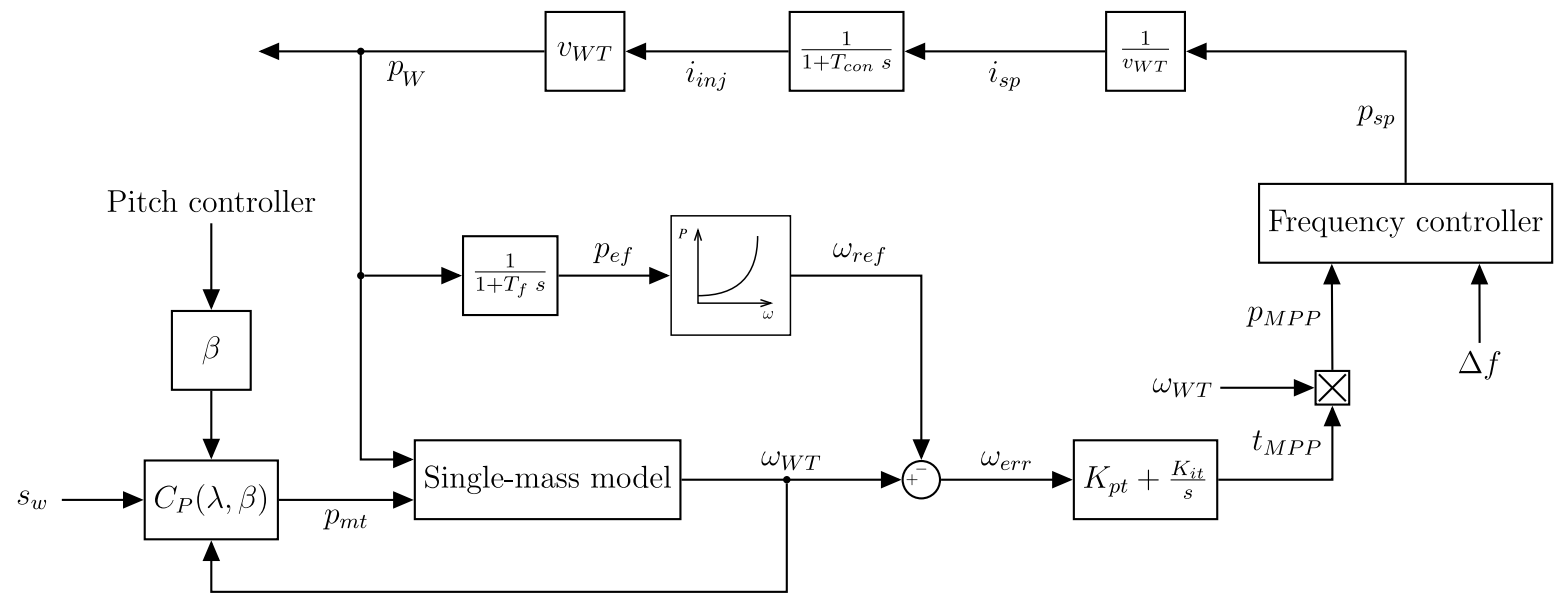

Figure 4. Block diagram of VSWT.

\subsection{Automatic Generation Control (AGC)}

The secondary control action removes the steady-state frequency error after the primary frequency control. It is modeled similar to [70]. The total secondary regulation effort $(\triangle R R)$ is obtained from:

$$
\Delta R R=-\Delta f K_{f},
$$

being $K_{f}$ determined according to the European Network of Transmission System Operators for Electricity (ENTSO-E) recommendations [71]. This regulation effort is distributed among each $i$ synchronized thermal unit as a function of their participation factors $\left(K_{u, i}\right)$, which are related to the speed droop of each unit [72]. Subsequently, the result of adding all $K_{u, i}$ must be one: 


$$
\Delta p_{i}^{r e f}=\frac{1}{T_{u, i}} \int \Delta R R K_{u, i} d t=\frac{-1}{T_{u, i}} \int K_{u, i} K_{f} d t,
$$

where $i$ represents $g a s, c c$, die, and st respectively. All thermal units connected to the grid participate in secondary control, whereas the participation factors of those units not connected are considered as zero, $K_{u, i}=0$.

\section{Adaptive Frequency Control Strategy-Methodology}

The adaptive control approach proposed in this work tries to minimize the effort of VSWTs when providing frequency response. The proposed approach is based on the fast power reserve technique. This control strategy distinguishes two different periods after a sudden power imbalance: (i) overproduction and (ii) recovery. During overproduction, the stored kinetic energy in the rotating masses of the VSWTs is supplied to the grid as an additional active power $\Delta p$ during a few seconds, being thus $p_{w}$ over $p_{M P P}\left(s_{w}\right)$. Subsequently, the rotational speed $\omega$ is reduced. Different definitions of this $\Delta p$ have been proposed. In fact, some authors consider $\Delta p$ as a fixed constant value [48-51], whereas others propose to estimate $\Delta p$ as dependent on the torque limit [52] or proportional to the frequency excursion [53]. The recovery period aims to restore $\omega$ to the prefault rotational speed value $\omega_{0}$. To overcome this, $p_{w}$ should be reduced below $p_{\text {mech }}(\omega)$. Previous proposals specified an underproduction power $p_{U P}$ by different ways, being thus the supplied power of each VSWTs: $p_{W}=p_{\text {mech }}-p_{U P}$.

In the proposed adaptive frequency control strategy, the initial value of $\Delta p$ for the overproduction period is related to the power system conditions. The authors propose a new frequency control approach based on the methodology followed in [73]. This reference estimates the exact and minimum amount of load needed to be shed after an imbalance depending on the RoCoF. In fact, a decision table that links the RoCoF with the strict amount of load shedding is developed based on presimulations. Then, the corresponding load shedding is activated after a contingency, tripping some amount of load demand immediately [74]. In this case, the proposed adaptive controller is based on a decision table that estimates the accurate value of $\Delta p$ for the VSWT overproduction.

The first step to formulate the decision table consists of defining several simulation scenarios that reflect the variability of the demand, the scheduling units, and/or the wind power penetration. To estimate the overproduction power $\Delta p$ after the outage of a thermal group, an iterative process is proposed for each scenario (see Figure 5). The condition considered to calculate such $\Delta p$ is that frequency $f$ should not be below a certain limit $f_{\text {lim }}$ for longer than a preset time limit $t_{\text {lim }}$. Both values $f_{l i m}$ and $t_{l i m}$ are related to the load shedding program of the power system. A counter is thus triggered when $f$ is below $f_{\text {lim }}$, computing the time that frequency is under that $f_{\text {lim }}$. Initially, the $i$-scenario is simulated assuming that the overproduction power in the first iteration $j$ is equal to $0\left(\Delta p_{j}=0\right)$. If $f$ is below $f_{\text {lim }}$ for longer than $t_{\text {lim }}, \Delta p_{j}$ is increased by a fixed value $\Delta p_{\text {inc }}$ with respect to the previous iteration $\left(\Delta p_{j}=\Delta p_{j-1}+\Delta p_{i n c}\right)$ and the same $i$-scenario is simulated again with the new value of $\Delta p_{j}$. When the condition is satisfied (i.e., $f$ is below $f_{\text {lim }}$ less time that $t_{l i m}$ ), the minimum $\Delta p$ for the $i$-scenario $\left(\Delta p_{i}\right)$ that VSWTs should provide has been determined $\left(\Delta p_{i}=\Delta p_{j}\right)$. Note that the overproduction power $\Delta p$ is supplied with a delay of $200 \mathrm{~ms}$, in order to have the measure of the RoCoF and in line with the delay time-interval in between 50 and $500 \mathrm{~ms}$ suggested in [75]. Once all the $\Delta p$ values have been determined from the simulations, a mathematical relationship between such $\Delta p$ and other variables of the power system need to be found. The obtained expression will be the decision table for the adaptive controller. 


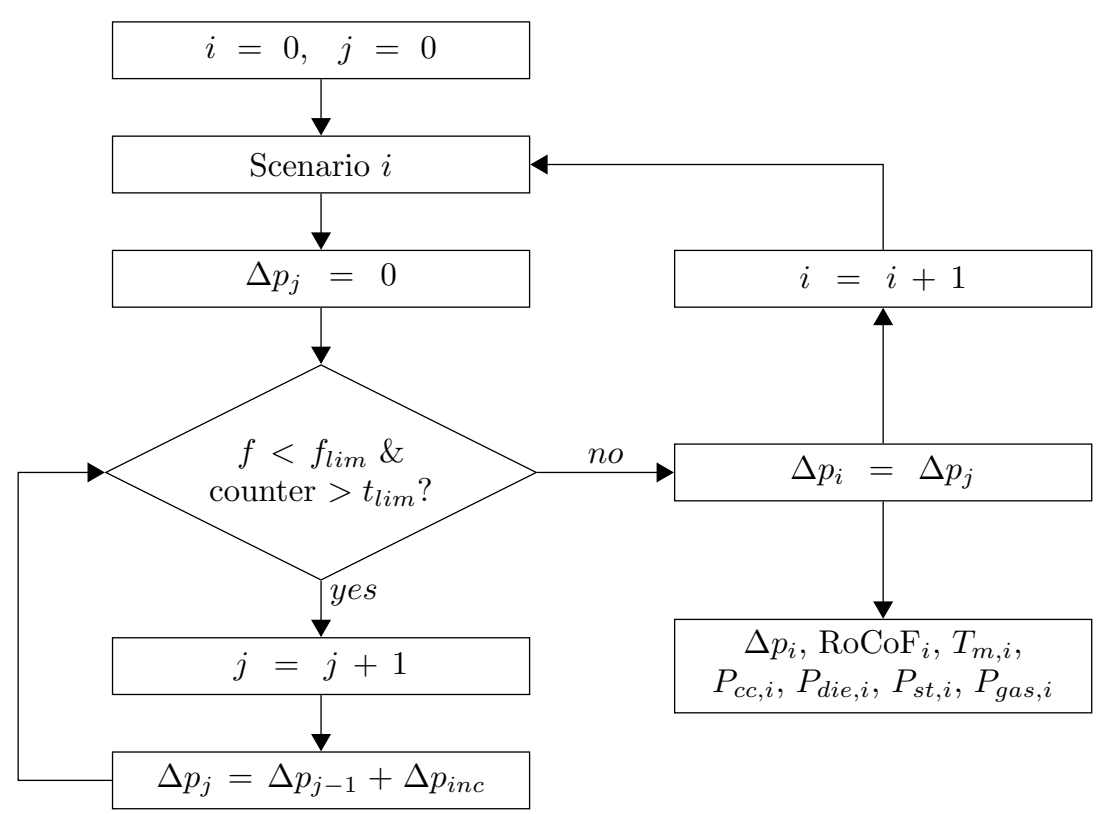

Figure 5. Flow-chart to estimate the overproduction of VSWTs.

When a power imbalance occurs, the VSWTs' controller determines the overproduction power $\Delta p$ according to the previous decision table. This situation causes a sudden $p_{w}$ increase and, after that, the supplied power starts to decrease. In this approach, instead of "forcing" the recovery period, the transition to recovery is carried out by the rotor speed PI controller in the converter, which slowly reduces the active power to achieve again $p_{M P P}\left(s_{w}\right)$. In order to avoid a fast power change, that could cause a secondary frequency dip, $K_{p t}$ and $K_{i t}$ (proportional and integral constants of the converter, refer to Figure 4) must be conveniently tuned. As a consequence, instead of fixing a $p_{U P}$ or defining an underproduction trajectory, the converter should adapt both the electrical power and the rotational speed to make them return to their pre-event values. Figure 6 presents the evolution of $P_{W}$ and $\omega$ under an imbalanced situation with the proposed approach, pointing out the overproduction and recovery periods.

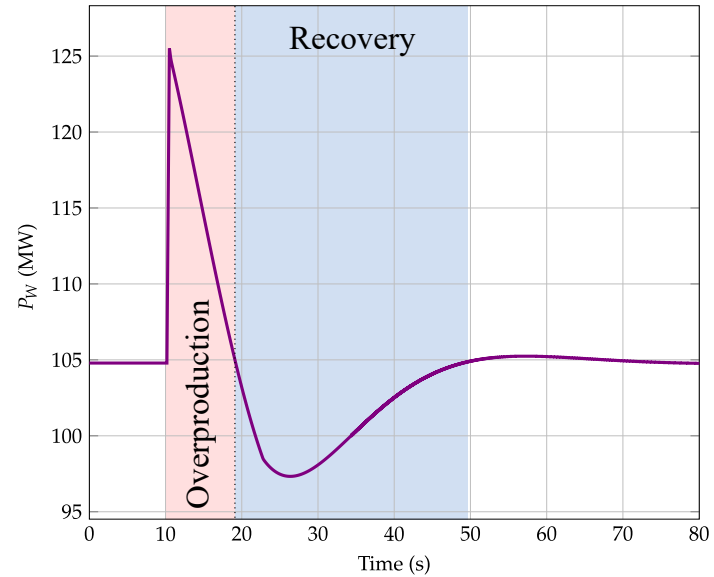

(a)

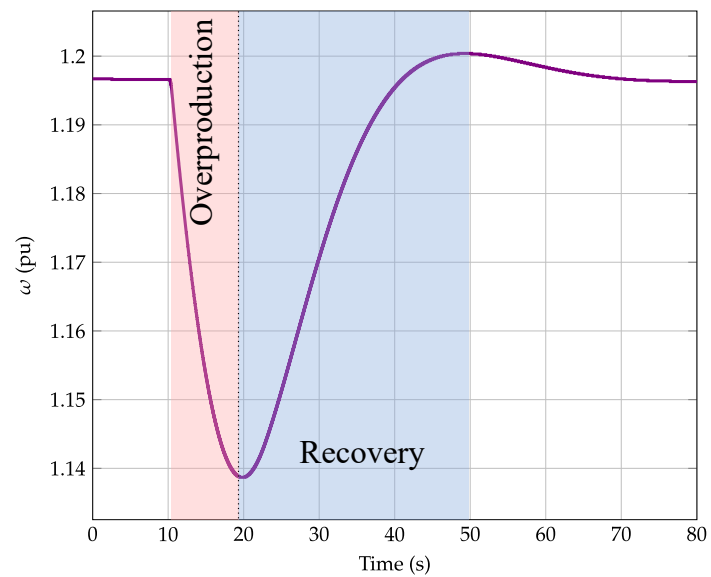

(b)

Figure 6. Example of overproduction and recovery periods. (a) Electrical power (MW); (b) Rotational speed (pu). 


\section{Case Study-Results}

The VSWT adaptive control strategy proposed in this study is applied to the Gran Canaria power system. Gran Canaria Island belongs to Spanish Canarian archipelago, being thus an isolated power system. Its electrical generation has always been based on fossil fuels from two power plants: Jinámar and Barranco de Tirijana power plants. These power plants included diesel, steam, gas, and combined cycle units. However, in recent decades, the government started to promote wind power plants installation, doubling its capacity up to $180 \mathrm{MW}$ since 2017. Table 1 lists each thermal unit capacity of the Gran Canaria power system.

Table 1. Gran Canaria thermal units power.

\begin{tabular}{|c|c|c|c|c|c|c|c|}
\hline \multicolumn{2}{|c|}{ Steam } & \multicolumn{2}{|c|}{ Gas } & \multicolumn{2}{|c|}{ Combined Cycle } & \multicolumn{2}{|c|}{ Diesel } \\
\hline$P_{s t, 1}$ & $72.4 \mathrm{MW}$ & $P_{g a s, 1}$ & $32.3 \mathrm{MW}$ & $P_{\mathcal{C C}, 1}$ & 206.1 MW & $P_{d i e, 1}$ & $8.5 \mathrm{MW}$ \\
\hline$P_{s t, 2}$ & $72.4 \mathrm{MW}$ & $P_{g a s, 2}$ & $32.3 \mathrm{MW}$ & $P_{c c, 2}$ & $227.0 \mathrm{MW}$ & $P_{d i e, 2}$ & 8.5 MW \\
\hline$P_{s t, 3}$ & $55.6 \mathrm{MW}$ & $P_{g a s, 3}$ & 17.3 MW & & & $P_{d i e, 3}$ & $8.5 \mathrm{MW}$ \\
\hline \multirow[t]{2}{*}{$P_{s t, 4}$} & $55.6 \mathrm{MW}$ & $P_{g a s, 4}$ & 32.3 MW & & & $P_{d i e, 4}$ & $20.5 \mathrm{MW}$ \\
\hline & & $P_{g a s, 5}$ & $32.3 \mathrm{MW}$ & & & $P_{d i e, 5}$ & $20.5 \mathrm{MW}$ \\
\hline
\end{tabular}

\subsection{Scenarios under Consideration}

Thirty different generation mixes of supply-side programs are under study for different demands and wind power generation. The generation mix scenarios are taken from [59], where a unit commitment model was also included. Figure 7 presents the different supply-side energy schedule of each program. From these generation mix scenarios, two different imbalance conditions are defined: (i) the loss of the largest power plant and (ii) the loss of the second largest power plant. In this way, a total of sixty different scenarios are analyzed. Figure 8 summarizes the supply-side after the disconnection of the largest and second largest units. In addition, it also points out the percentage that represents the loss of each unit over the total system demand.

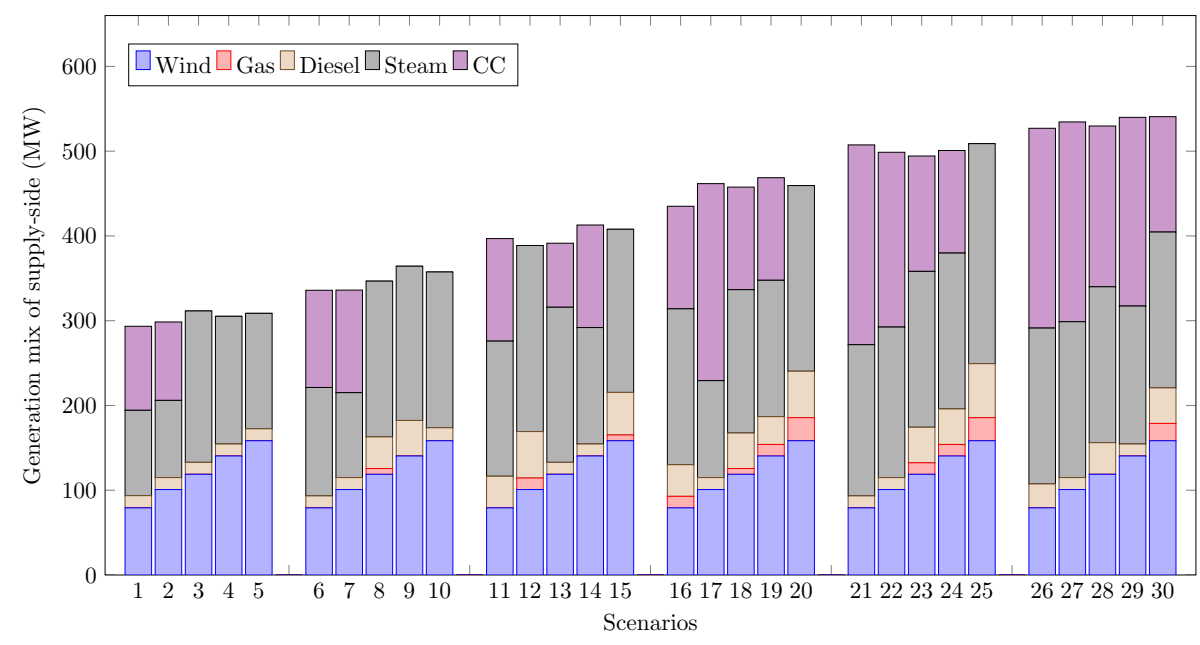

Figure 7. Generation mix scenarios under consideration. 


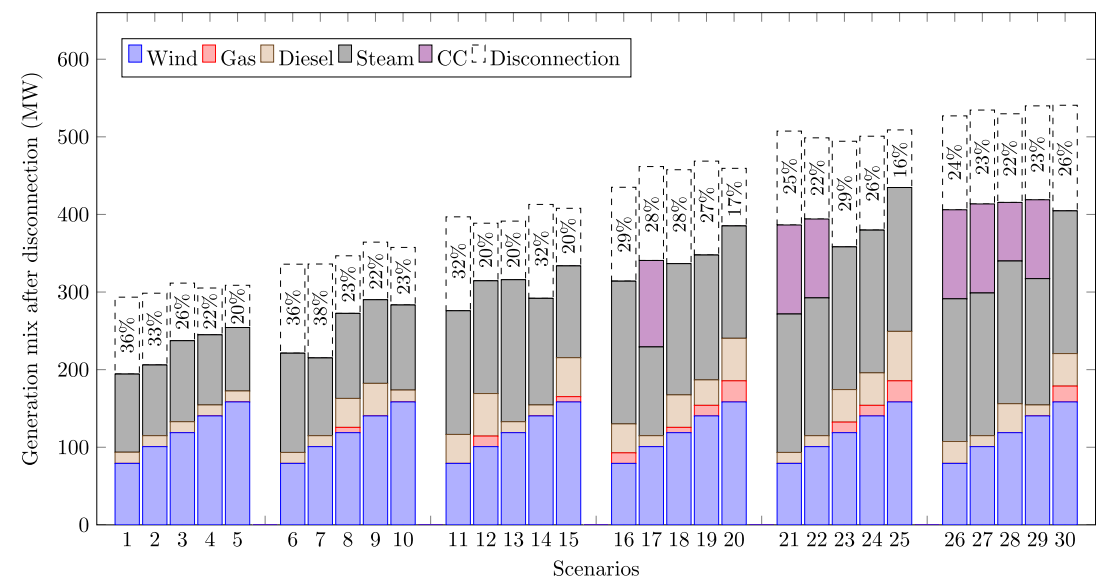

(a)

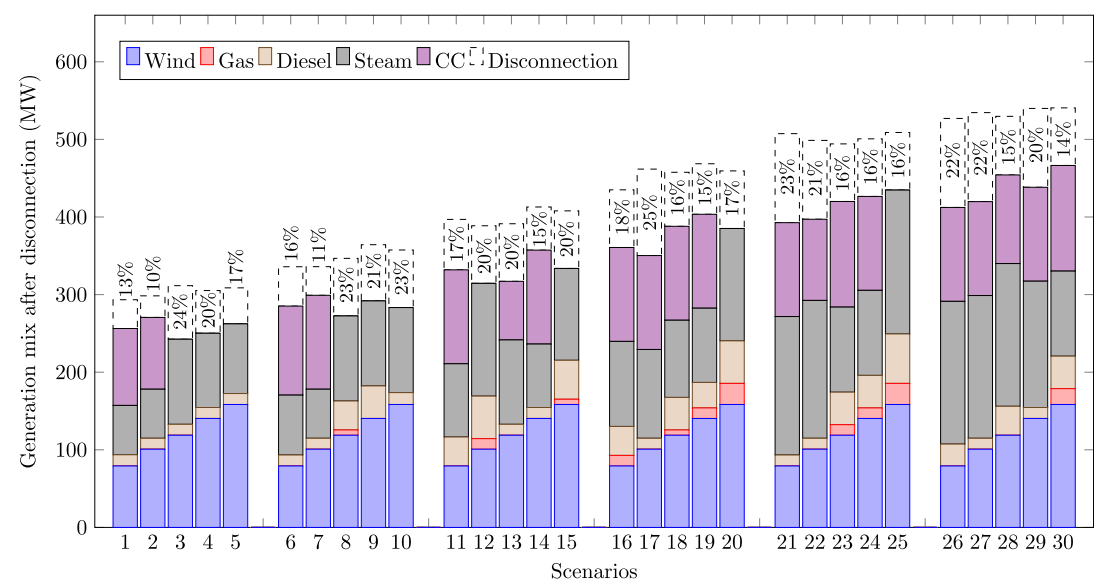

(b)

Figure 8. Generation mix after disconnection (a) Largest power plant disconnection. (b) Second largest power plant disconnection.

\subsection{Decision Table Definition: Regression Analysis}

From the sixty scenarios presented in Section 4.1, the corresponding $\Delta p$ values are determined following Section 3. In this work, and according to the load shedding scheme presented in [59], $f_{\text {lim }}=49 \mathrm{~Hz}, t_{\text {lim }}=1 \mathrm{~s}$ and $\Delta p_{\text {inc }}=0.01 \mathrm{pu}$ for the Gran Canaria island power system. A mathematical relationship between such $\Delta p$ and other variables of the power system need to be found. As aforementioned, [73] proposed to relate the power to be shed with the RoCoF by a linear and quadratic regression, with $R^{2}=0.951$ and $R^{2}=0.969$, respectively. However, both the linear regression and the quadratic regression of $\Delta P$ and RoCoF for this case study accounted for low values of $R^{2}: R^{2}=0.433$ for linear regression and $R^{2}=0.512$ for quadratic regression. As a consequence, other variables are introduced in the proposed mathematical lineal regression. By also considering the electrical power of each thermal technology assigned in the scheduled program, the system synchronous inertia before the incident, and neglecting all those cases in which the estimated $\Delta p$ was $\Delta p=0$, the coefficient of determination increased to $R^{2}=0.801$ following Equation (4):

$$
\Delta P=-386.15+108.63 \cdot \operatorname{RoCoF}-1.32 \cdot P_{\text {gas }}+0.26 \cdot P_{\text {die }}+0.65 \cdot P_{s t}-0.42 \cdot P_{c c}+32.92 \cdot T_{m},
$$

being $\Delta P$ in MW, RoCoF in $\mathrm{Hz} / \mathrm{s}, P_{i}$ in MW ( $i$ stands for $g a s, c c$, die and $s t$ ), and $T_{m}$ in s.

Comparing the results of $\Delta P$ obtained from the simulations and those estimated with Equation (4), two additional conditions were included: 
1. If the power supplied by the combined cycle power plants before the imbalance was over $180 \mathrm{MW}$ $\left(P_{c c, 0}>180 \mathrm{MW}\right), \Delta P=0$

2. If the estimated $\Delta P$ with the regression is negative $(\Delta P<0), \Delta P=0$

Moreover, the maximum overproduction power $\Delta P$ of the wind power plant was considered as $20 \%$ over the installed capacity of the wind power plant, $\Delta P_{\max }=0.2 \cdot P_{w}$.

\subsection{Results}

Apart from the adaptive control approach, other frequency strategies have been simulated and compared for the sixty scenarios under consideration:

1. Frequency control only provided by thermal power plants (referred to as without VSWTs).

2. Frequency control provided by thermal power plants and VSWTs. The overproduction is defined as proportional to $\Delta f$; change from overproduction to recovery period occurs when $\omega / \omega_{0}<0.9$, and $p_{U P}=0.05 \mathrm{pu}$ (fast power reserve technique). It is triggered when $\Delta f \geq 100 \mathrm{mHz}$ and the maximum $\Delta p=0.15 \cdot p_{\text {mech }}(\omega)$ (referred to as previous approach).

3. Frequency control provided by thermal power plants and VSWTs using the proposed control approach (referred to as adaptive approach).

As was discussed in Section 4.1, sixty different scenarios are considered to evaluate the new frequency control approach for VSWTs. Results are focused on four different aspects for each scenario: (i) the minimum rotational speed $\omega_{\min }$; (ii) the maximum torque $T_{\max }$; (iii) the power shed due to the corresponding load shedding programs; (iv) number of cases in which VSWTs do not participate in frequency control with the adaptive proposed approach. Both $\omega_{\min }$ and $T_{\max }$ are expressed in $\%$ with regard to the pre-event values, which is equal to their values when they do not participate in frequency control.

Figure 9 depicts the range values of the rotational speed in \% compared to the pre-event value. When VSWTs do not participate in frequency control, its $\omega$ variation is null, as they are providing $p_{M P P}\left(s_{w}\right)$. According to these results, and depending on the frequency control strategy, important differences can be identified. With regard to the frequency control referred to as previous approach, and considering that the change from overproduction to recovery period is always with $\omega / \omega_{0}<0.9$, all scenarios then give the same minimum $\omega$, which represents more than a $7 \%$ variation. Based on the adaptive approach, $\omega_{\min }$ variations range in between 0 (for those cases in which the frequency control is not activated) and $6.62 \%$. In fact, the average $\omega_{\min }$ variation with the proposed strategy is $2.15 \%$. As a consequence, the new frequency control strategy technique does not only optimize those imbalances where VSWTs frequency control participation is required but also reduces the averaged variation of $\omega$ to more than half of the previous frequency control approaches.

Figure 10 compares the maximum torque during the VWST frequency response to the corresponding pre-event value. These results are in line with the previous rotational speed comparison, see Figure 9. The torque does not vary when VSWTs do not participate in frequency control, as both $\omega$ and $p_{e}$ remain constant. With the previous approach for VSWT frequency control, the maximum torque variation is always the same. Moreover, this variation is over a $30 \%$ increase-in comparison to the pre-event value, which can address relevant mechanical loads on the turbine shaft. In contrast, with the proposed adaptive approach, the maximum $T_{\max }$ variation is $26.5 \%$ (only 9 out of 60 scenarios), with an average $T_{\max }$ of $9.7 \%$. It can be then deduced that the new frequency control approach does not only avoid the activation of the frequency control of VSWTs in most of imbalance scenarios but also that both $\omega$ and $T_{\max }$ ranges are reduced significantly compared to previous approaches. 


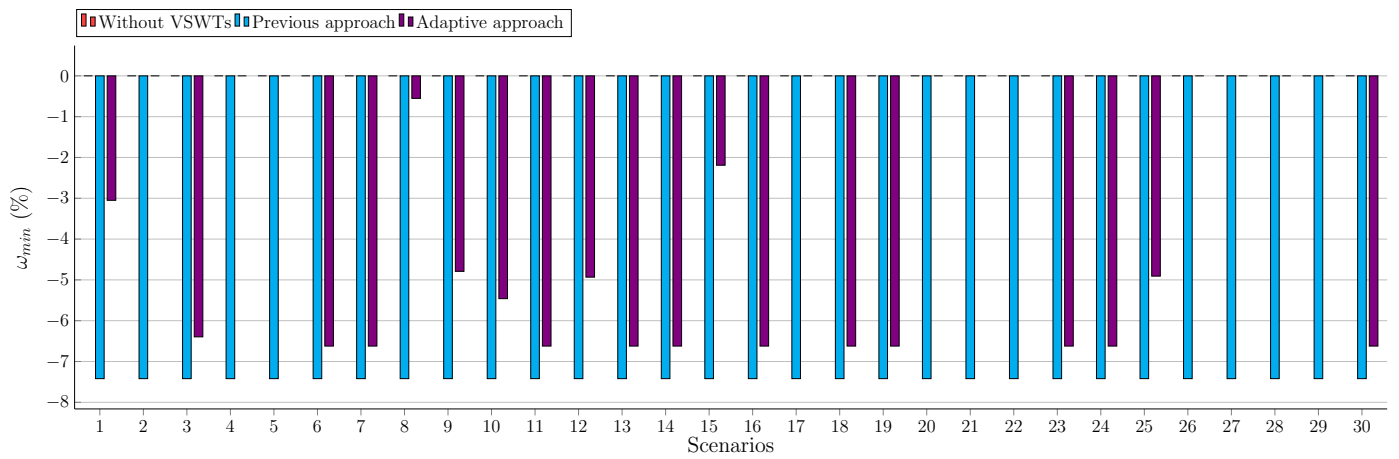

(a)

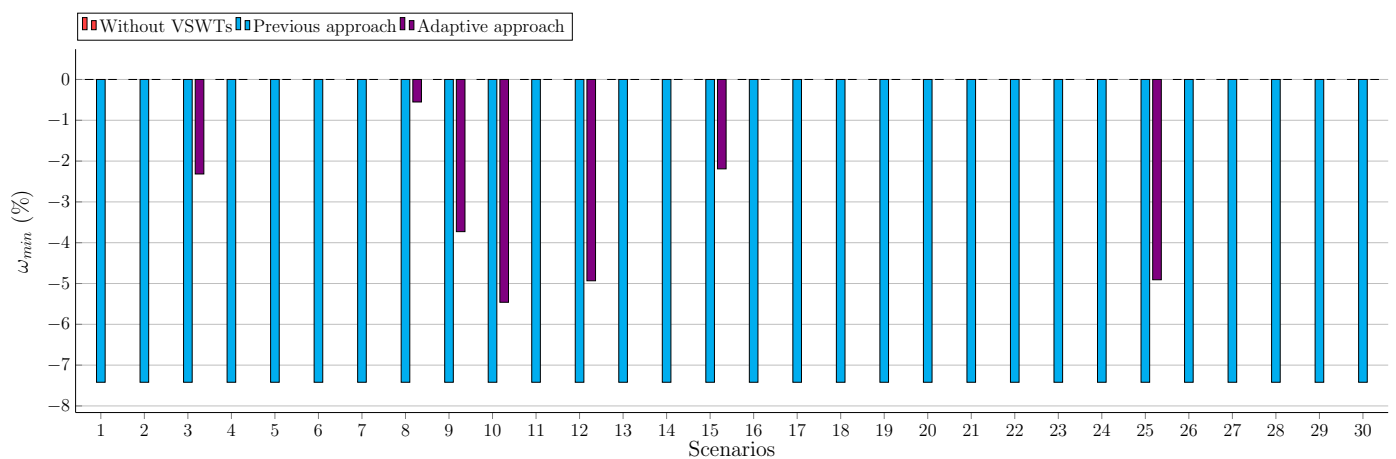

(b)

Figure 9. Minimum rotational speed (a) Largest power plant disconnection; (b) Second largest power plant disconnection.

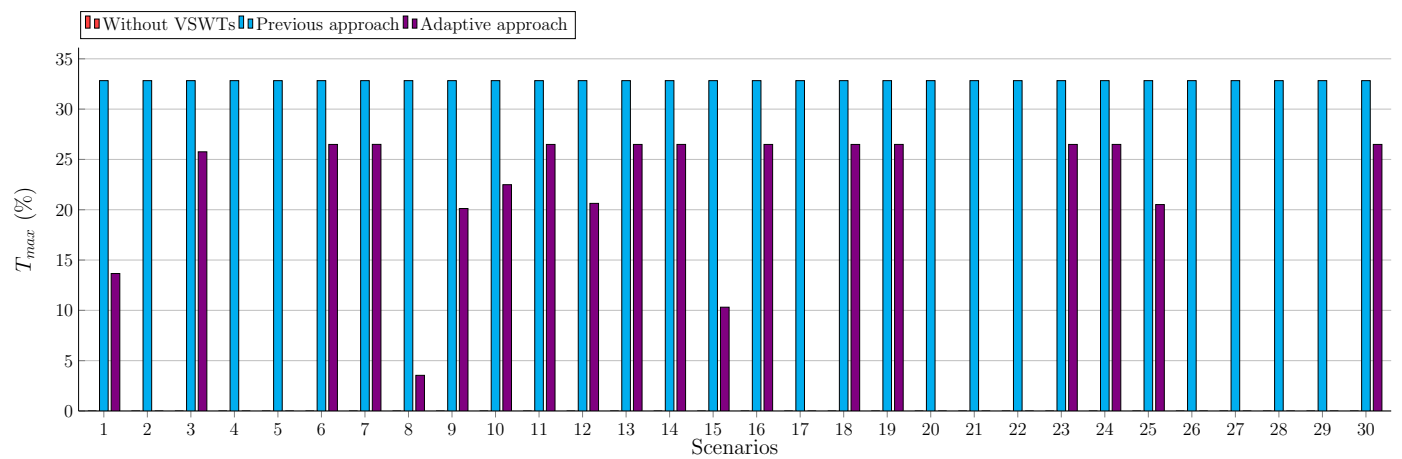

(a)

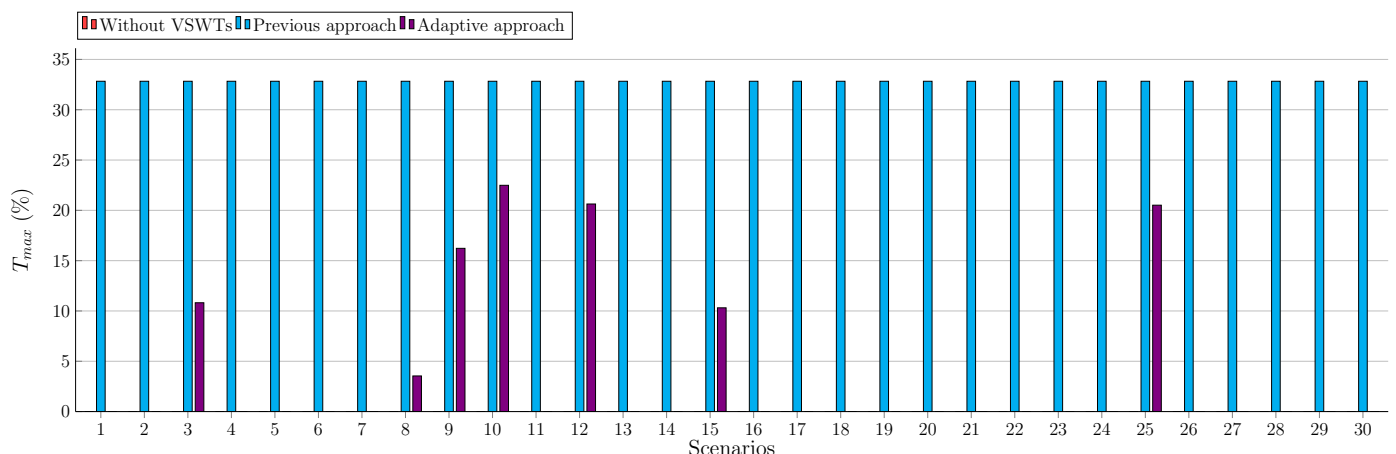

(b)

Figure 10. Maximum torque variation (a) Largest power plant disconnection; (b) Second largest power plant disconnection. 
Figure 11 shows the power shed by the load shedding program. As can be seen, it is reduced when wind power plants participate in frequency control, compared to the current case in which only thermal power plants are providing such ancillary service. Comparing the two different frequency control approaches analyzed, small differences are found. The previous approach gets better results in 4 out of 60 scenarios under study, whereas the adaptive approach obtained lower load shedding values in 2 out of 60 scenarios. In the other cases, both frequency controllers obtain the same load shedding.

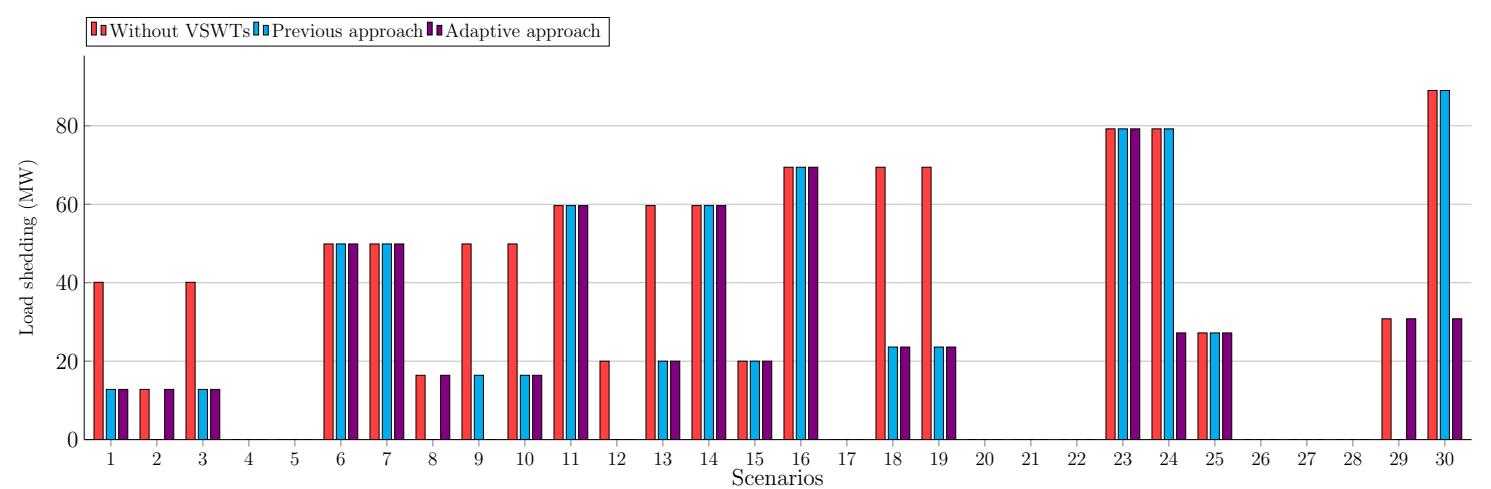

(a)

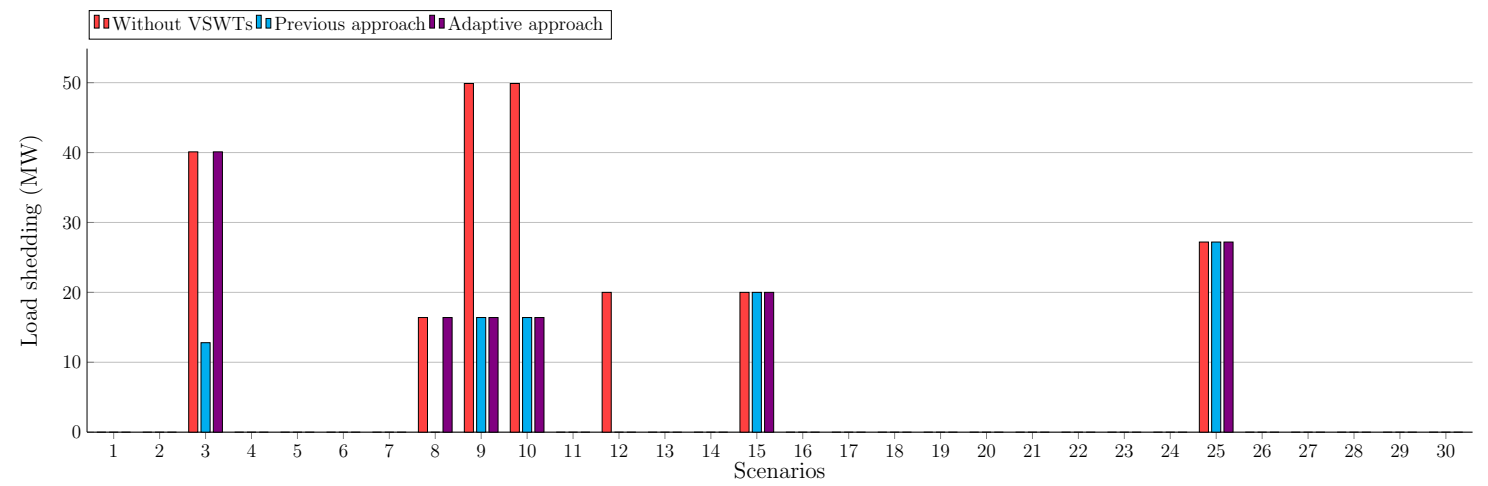

(b)

Figure 11. Load shedding (a) Largest power plant disconnection; (b) Second largest power plant disconnection.

Finally, 57\% of imbalances without any VSWTs frequency response participation have been identified. These results reduce significantly the mechanical and electrical VSWT efforts under imbalances, maintaining similar frequency excursions to the previous control strategies. More specifically, the VSWT frequency participation is not required to provide additional power in 11 out of 30 for the largest power plant loss and 23 out of 30 for the second largest power plant loss. These 34 scenarios where the adaptive frequency control is not triggered can be seen in Figures 9 and 10: imbalance scenarios will null variation of $\omega_{\min }$ and $T_{\max }$ for the proposed control strategy. Therefore, $p_{e}$ and $\omega$ values keep as constant during the imbalance and, subsequently, also maintain the torque. In addition, authors have checked that in $94 \%$ of the cases in which VSWTs are not participating in frequency control with the adaptive approach, the power shed was initially null, pointing out that their participation was not required within acceptable frequency excursion ranges.

As an additional result, Figures 12-14 depict the frequency evolution, load shedding, wind power, and rotational speed for scenarios 9, 16, and 27, respectively, for the loss of the largest power plant. Together with the aforementioned advantages of the new approach, authors also point out that the rotational speed of VSWTs is recovered in a lower time interval than with the previous frequency control approach. Moreover, the transition from overproduction to recovery period is also smoother, avoiding undesirable secondary frequency dips (refer to Figure 12). 


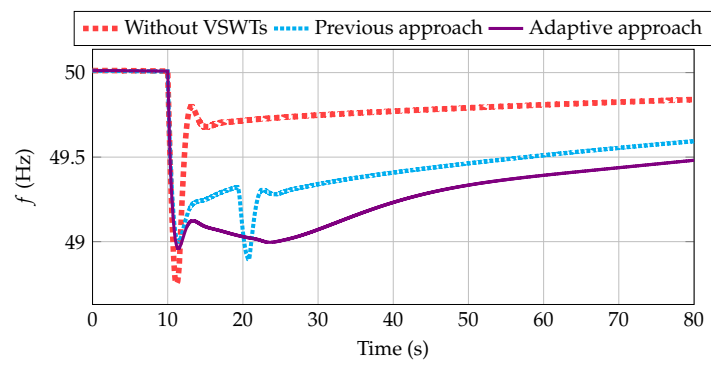

(a)

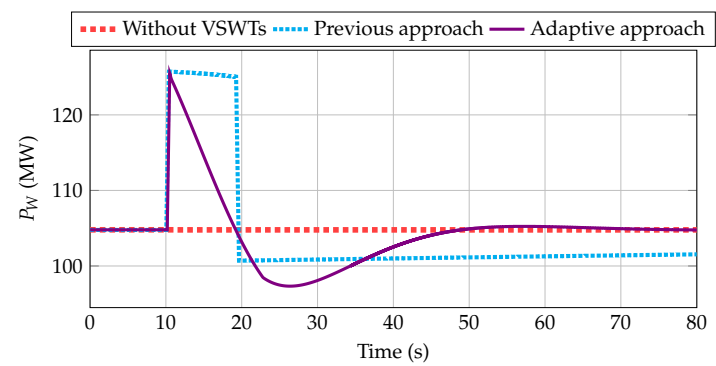

(c)

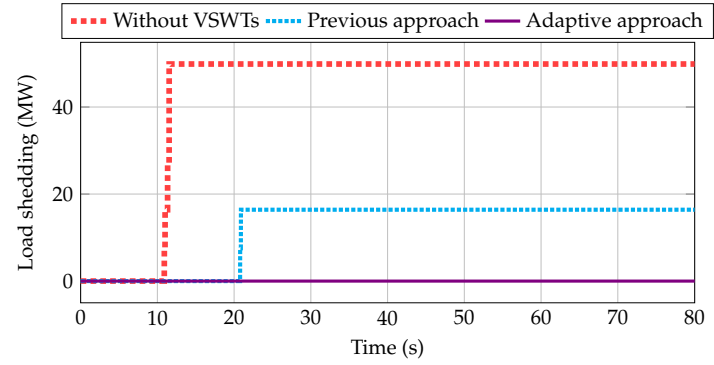

(b)

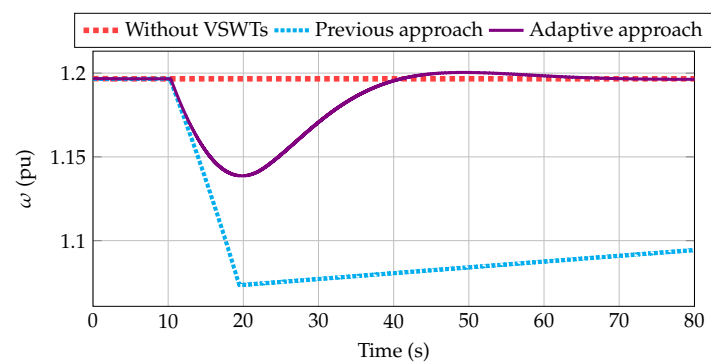

(d)

Figure 12. Results for scenario 9 (a) Frequency (Hz). (b) Load shedding (MW) (c) Wind power (MW) (d) VSWTs rotational speed (pu).

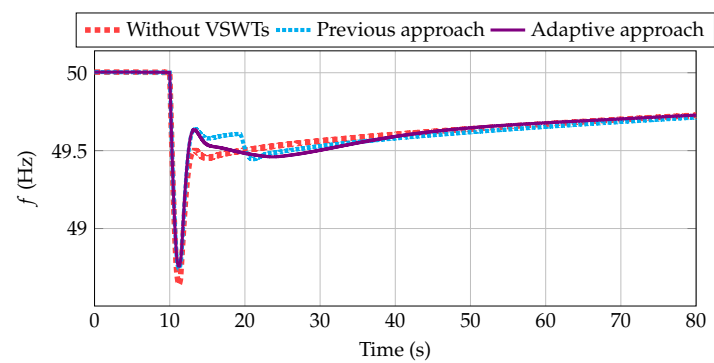

(a)

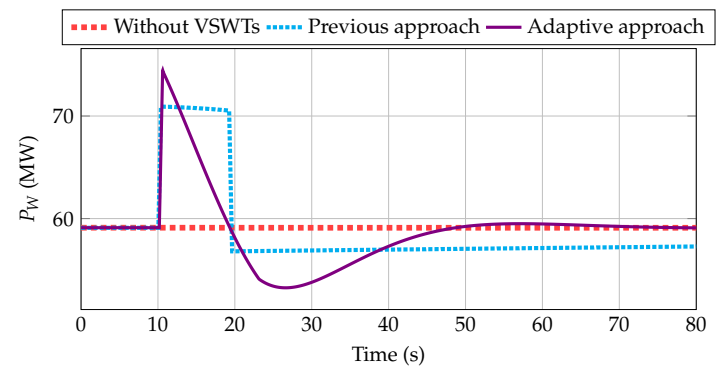

(c)

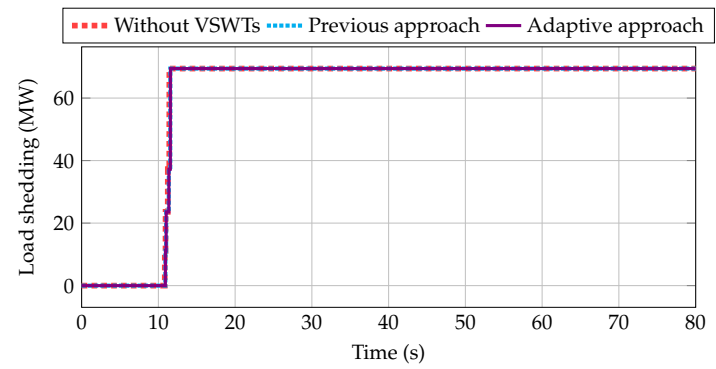

(b)

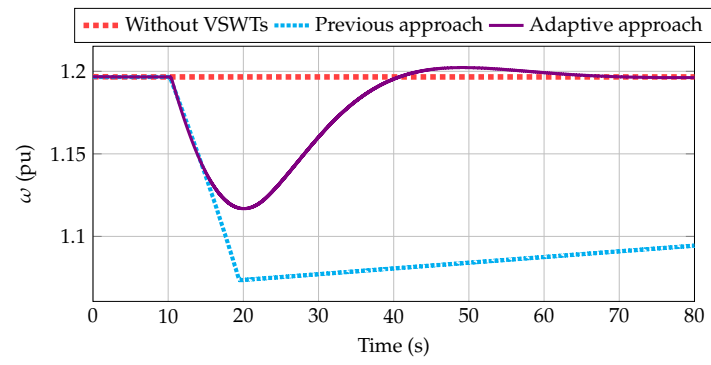

(d)

Figure 13. Results for scenario 16 (a) Frequency (Hz); (b) Load shedding (MW); (c) Wind power (MW); (d) VSWTs rotational speed $(\mathrm{pu})$. 


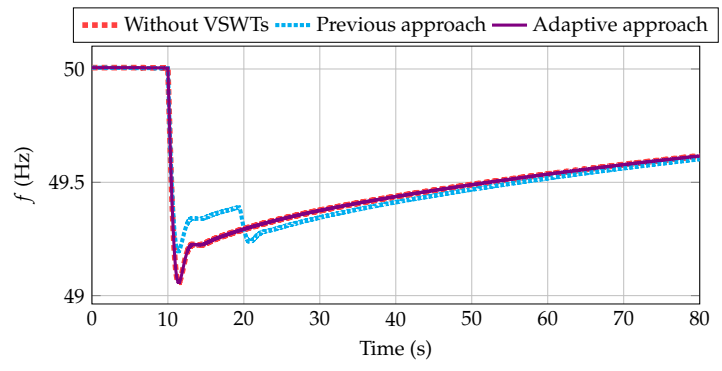

(a)

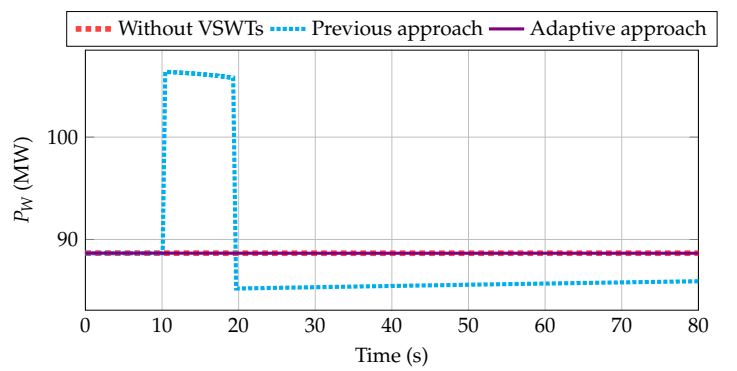

(c)

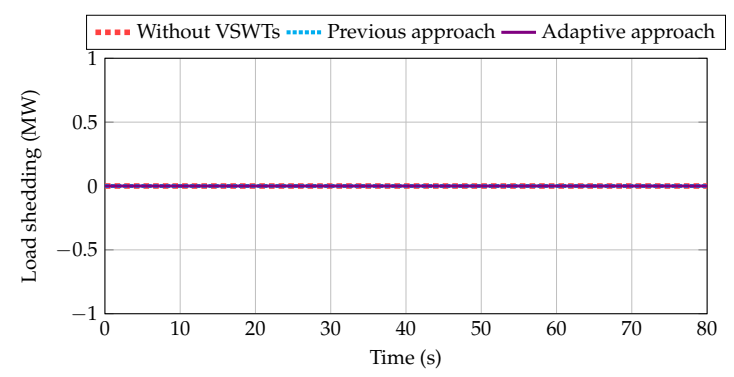

(b)

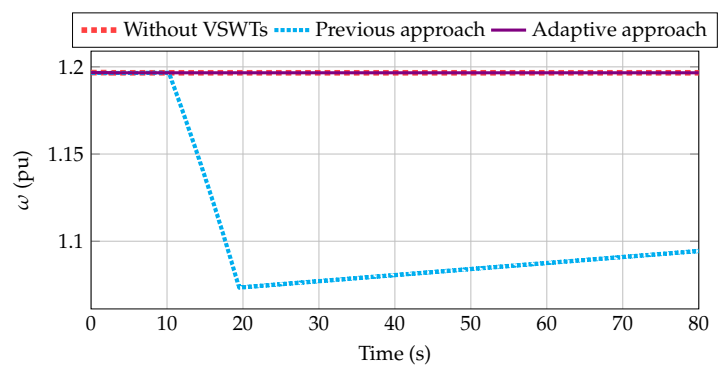

(d)

Figure 14. Results for scenario 27 (a) Frequency (Hz); (b) Load shedding (MW); (c) Wind power (MW); (d) VSWTs rotational speed (pu).

\section{Conclusions}

Due to the massive penetration of VSWTs, their contribution to frequency regulation has become a need. As isolated power systems have low synchronous inertia, VSWTs frequency control is even more required. Even though different control strategies for VSWTs have been proposed in the last decade, they usually imply important drawbacks in terms of efficiency, economic profits, and/or equipment wear. As a result, with the aim of reducing the mechanical stress of VSWTs providing frequency response, an adaptive control strategy is proposed in this work. Our approach is based on estimating the minimum overproduction power provided by VSWTs following a linear regression estimation. In this way, such overproduction power depends on some grid parameters (i.e., RoCoF, synchronous inertia, and assigned power of thermal units before the incident). The proposed controller is compared to a conventional fast power reserve strategy. The Gran Canaria isolated power system (Spain) is considered as case study, analyzing sixty representative imbalance scenarios. Results show that similar values for the power shed with the load shedding program are obtained with the two approaches. However, the new adaptive control reduces the VSWTs maximum torque variations and the speed variations ( $23 \%$ and $5 \%$ on average, respectively), in comparison to the conventional VSWTs frequency control strategy. This is due to the smoother transition from overproduction to recovery periods, which reduces the electrical and mechanical VSWT efforts. In addition, in $57 \%$ of the imbalance scenarios under consideration, VSWTs are not required to participate in frequency response. Thus, both electrical power and rotational speed are kept as constants (subsequently maintaining the torque). As a result, a longer life span is expected for the VSWTs electrical and mechanical components.

Author Contributions: Conceptualization, J.I.S.; Data curation, A.F.-G.; Formal analysis, G.M.-L.; Investigation, A.F.-G.; Methodology, J.I.S.; Resources, A.F.-G. and G.M.-L.; Software, A.F.-G.; Supervision, Á.M.-G. and J.I.S.; Validation, G.M.-L. and J.I.S.; Visualization, Á.M.-G.; Writing—original draft, A.F.-G. and G.M.-L.; Writing-review and editing, A.M.-G. and J.I.S. All authors have read and agreed to the published version of the manuscript. 
Funding: This work was partially supported by 'Ministerio de Educación, Cultura y Deporte' of Spain (ref. FPU16/04282) and by 'Ministerio de Economía y Competitividad', under the project "Value of pumped-hydro energy storage in isolated power systems with high wind power penetration" of the National Plan for Scientific and Technical Research and Innovation 2013-2016, grant number ENE2016-77951-R.

Conflicts of Interest: The authors declare no conflict of interest.

\section{Abbreviations}

The following abbreviations are used in this manuscript:

$\beta \quad$ Pitch angle (grades)

$\omega \quad$ Rotational speed (p.u.)

$\triangle P \quad$ Overproduction power of VSWT (MW)

$\triangle R R \quad$ Total secondary regulation effort

$f \quad$ Frequency $(\mathrm{Hz})$

$p \quad$ Active power (p.u.)

$s_{w} \quad$ Wind speed $(\mathrm{m} / \mathrm{s})$

$D_{\text {net }} \quad$ Damping factor of loads

$K_{u} \quad$ Participation factor in secondary control

$P \quad$ Active power (MW)

$T_{m} \quad$ Inertia constant (s)

$0 \quad$ Pre-event value (subscript)

$c c \quad$ Combined cycle (subscript)

dem Demand (subscript)

die Diesel (subscript)

gas Gas (subscript)

$\max$ Maximum value (subscript)

mech Mechanical (subscript)

min Minimum value (subscript)

st Steam (subscript)

ther Thermal (subscript)

$w \quad$ Wind (subscript)

UP Underproduction (subscript)

AGC Automatic Generation Control

II-RES Inverter Interfaced Renewable Energy Sources

MPP Maximum Power Point

PV Photovoltaic

RoCoF Rate of Change of Frequency

TSO Transmission System Operator

VSWT Variable Speed Wind Turbine

\section{References}

1. Kaushal, A.; Van Hertem, D. An Overview of Ancillary Services and HVDC Systems in European Context. Energies 2019, 12, 3481. [CrossRef]

2. Martínez-Lucas, G.; Sarasúa, J.I.; Wilhelmi, J.R.; ángel Sánchez, J. Contribution to load-frequency regulation of a hydropower plant with long tail-race tunnel. In Proceedings of the 15th International Conference on Environment and Electrical Engineering (EEEIC), Rome, Italy, 10-13 June 2015; pp. 1886-1891.

3. Qi, Y.; Wang, D.; Wang, X.; Jia, H.; Pu, T.; Chen, N.; Liu, K. Frequency control ancillary service provided by efficient power plants integrated in Queuing-Controlled domestic water heaters. Energies 2017, 10, 559. [CrossRef]

4. ENTSO-E. Electricity Balancing in Europe. Available online: https://docstore.entsoe.eu/ (accessed on 15 April 2020).

5. Das, K.; Nitsas, A.; Altin, M.; Hansen, A.D.; Sørensen, P.E. Improved load-shedding scheme considering distributed generation. IEEE Trans. Power Deliv. 2016, 32, 515-524. [CrossRef] 
6. Tofis, Y.; Timotheou, S.; Kyriakides, E. Minimal load shedding using the swing equation. IEEE Trans. Power Syst. 2016, 32, 2466-2467. [CrossRef]

7. Costa, M.H.; Ravetti, M.G.; Saldanha, R.R.; Carrano, E.G. Minimizing undesirable load shedding through robust coordination of directional overcurrent relays. Int. J. Electr. Power Energy Syst. 2019, 113, 748-757. [CrossRef]

8. Rudez, U.; Mihalic, R. RoCoF-based improvement of conventional under-frequency load Shedding. In Proceedings of the 2019 IEEE Milan PowerTech, Milan, Italy, 23-27 June 2019; pp. 1-5.

9. Fernández-Guillamón, A.; Molina-García, A.; Vigueras-Rodríguez, A.; Gómez-Lázaro, E. Frequency response and inertia analysis in power systems with high wind energy integration. In Proceedings of the 2019 International Conference on Clean Electrical Power (ICCEP), Otranto, Italy, 2-4 July 2019; pp. 388-393.

10. Fernández-Guillamón, A.; Vigueras-Rodríguez, A.; Molina-García, Á. Analysis of power system inertia estimation in high wind power plant integration scenarios. IET Renew. Power Gener. 2019, 13, 2807-2816. [CrossRef]

11. Molina-García, A.; Fernández-Guillamón, A.; Gómez-Lázaro, E.; Honrubia-Escribano, A.; Bueso, M.C. Vertical Wind Profile Characterization and Identification of Patterns Based on a Shape Clustering Algorithm. IEEE Access 2019, 7, 30890-30904. [CrossRef]

12. Available online: https://gwec.net/global-wind-report-2019/ (accessed on 29 April 2020).

13. Muñoz-Benavente, I.; Hansen, A.D.; Gómez-Lázaro, E.; García-Sánchez, T.; Fernández-Guillamón, A.; Molina-García, Á. Impact of combined demand-response and wind power plant participation in frequency control for multi-area power systems. Energies 2019, 12, 1687. [CrossRef]

14. Tielens, P.; Van Hertem, D. The relevance of inertia in power systems. Renew. Sustain. Energy Rev. 2016, 55, 999-1009. [CrossRef]

15. Daly, P.; Flynn, D.; Cunniffe, N. Inertia considerations within unit commitment and economic dispatch for systems with high non-synchronous penetrations. In Proceedings of the 2015 IEEE Eindhoven PowerTech, Eindhoven, The Netherlands, 29 June-2 July 2015; pp. 1-6.

16. Martínez-Lucas, G.; Sarasúa, J.I.; Sánchez-Fernández, J.Á.; Wilhelmi, J.R. Power-frequency control of hydropower plants with long penstocks in isolated systems with wind generation. Renew. Energy 2015, 83, 245-255. [CrossRef]

17. Martinez-Lucas, G.; Sarasúa, J.I.; Sánchez-Fernández, J.Á.; Wilhelmi, J.R. Frequency control support of a wind-solar isolated system by a hydropower plant with long tail-race tunnel. Renew. Energy 2016, 90, 362-376. [CrossRef]

18. Toulabi, M.; Bahrami, S.; Ranjbar, A.M. An input-to-state stability approach to inertial frequency response analysis of doubly-fed induction generator-based wind turbines. IEEE Trans. Energy Convers. 2017, 32, 1418-1431. [CrossRef]

19. Fernández-Guillamón, A.; Gómez-Lázaro, E.; Muljadi, E.; Molina-García, Á. Power systems with high renewable energy sources: A review of inertia and frequency control strategies over time. Renew. Sustain. Energy Rev. 2019, 115, 109369. [CrossRef]

20. Alsharafi, A.S.; Besheer, A.H.; Emara, H.M. Primary Frequency Response Enhancement for Future Low Inertia Power Systems Using Hybrid Control Technique. Energies 2018, 11, 699. [CrossRef]

21. Fernández-Guillamón, A.; Vigueras-Rodríguez, A.; Gómez-Lázaro, E.; Molina-García, Á. Fast power reserve emulation strategy for VSWT supporting frequency control in multi-area power systems. Energies 2018, 11, 2775. [CrossRef]

22. Chen, Z.; Yin, M.; Zou, Y.; Meng, K.; Dong, Z. Maximum wind energy extraction for variable speed wind turbines with slow dynamic behavior. IEEE Trans. Power Syst. 2016, 32, 3321-3322. [CrossRef]

23. Ziping, W.; Wenzhong, G.; Tianqi, G.; Weihang, Y.; ZHANG, H.; Shijie, Y.; Xiao, W. State-of-the-art review on frequency response of wind power plants in power systems. J. Mod. Power Syst. Clean Energy 2017, 6, 1-16.

24. Fernández-Guillamón, A.; Gómez-Lázaro, E.; Muljadi, E.; Molina-Garcia, Á. A Review of Virtual Inertia Techniques for Renewable Energy-Based Generators. In Power Systems; IntechOpen: London, UK, 2020.

25. Yingcheng, X.; Nengling, T. Review of contribution to frequency control through variable speed wind turbine. Renew. Energy 2011, 36, 1671-1677. [CrossRef]

26. Ma, H.; Chowdhury, B. Working towards frequency regulation with wind plants: Combined control approaches. IET Renew. Power Gener. 2010, 4, 308-316. [CrossRef] 
27. Moutis, P.; Papathanassiou, S.A.; Hatziargyriou, N.D. Improved load-frequency control contribution of variable speed variable pitch wind generators. Renew. Energy 2012, 48, 514-523. [CrossRef]

28. Žertek, A.; Verbič, G.; Pantoš, M. Optimised control approach for frequency-control contribution of variable speed wind turbines. IET Renew. Power Gener. 2012, 6, 17-23. [CrossRef]

29. Martínez-Lucas, G.; Sarasúa, J.I.; Pérez-Díaz, J.I.; Martínez, S.; Ochoa, D. Analysis of the Implementation of the Primary and/or Inertial Frequency Control in Variable Speed Wind Turbines in an Isolated Power System with High Renewable Penetration. Case Study: El Hierro Power System. Electronics 2020, 9, 901. [CrossRef]

30. Castro, L.M.; Fuerte-Esquivel, C.R.; Tovar-Hernández, J.H. Solution of power flow with automatic load-frequency control devices including wind farms. IEEE Trans. Power Syst. 2012, 27, 2186-2195. [CrossRef]

31. Vidyanandan, K.; Senroy, N. Primary frequency regulation by deloaded wind turbines using variable droop. IEEE Trans. Power Syst. 2013, 28, 837-846. [CrossRef]

32. Zhang, X.; Zha, X.; Yue, S.; Chen, Y. A Frequency Regulation Strategy for Wind Power Based on Limited Over-Speed De-Loading Curve Partitioning. IEEE Access 2018, 6, 22938-22951. [CrossRef]

33. Wang, S.; Tomsovic, K. A Novel Active Power Control Framework for Wind Turbine Generators to Improve Frequency Response. IEEE Trans. Power Syst. 2018, 33, 6579-6589. [CrossRef]

34. Fang, X.; Krishnan, V.; Hodge, B.M. Strategic offering for wind power producers considering energy and flexible ramping products. Energies 2018, 11, 1239. [CrossRef]

35. Ye, H.; Pei, W.; Qi, Z. Analytical modeling of inertial and droop responses from a wind farm for short-term frequency regulation in power systems. IEEE Trans. Power Syst. 2016, 31, 3414-3423. [CrossRef]

36. Arani, M.F.; Mohamed, Y.A.I. Dynamic Droop Control for Wind Turbines Participating in Primary Frequency Regulation in Microgrids. IEEE Trans. Smart Grid 2017, 9, 5742-5751. [CrossRef]

37. Lertapanon, P.; Wangdee, W. Analysis and modeling of wind turbine generators considering frequency controls. In Proceedings of the Electrical Engineering Congress (iEECON), Pattaya, Thailand, 8-10 March 2017; pp. 1-4.

38. Huang, L.; Xin, H.; Zhang, L.; Wang, Z.; Wu, K.; Wang, H. Synchronization and Frequency Regulation of DFIG-Based Wind Turbine Generators With Synchronized Control. IEEE Trans. Energy Convers. 2017, 32, 1251-1262. [CrossRef]

39. Deepak, M.; Abraham, R.J.; Gonzalez-Longatt, F.M.; Greenwood, D.M.; Rajamani, H.S. A novel approach to frequency support in a wind integrated power system. Renew. Energy 2017, 108, 194-206. [CrossRef]

40. Margaris, I.D.; Papathanassiou, S.A.; Hatziargyriou, N.D.; Hansen, A.D.; Sorensen, P. Frequency control in autonomous power systems with high wind power penetration. IEEE Trans. Sustain. Energy 2012, 3, 189-199. [CrossRef]

41. Morren, J.; de Haan, S.W.H.; Kling, W.L.; Ferreira, J.A. Wind turbines emulating inertia and supporting primary frequency control. IEEE Trans. Power Syst. 2006, 21, 433-434. [CrossRef]

42. Díaz-González, F.; Hau, M.; Sumper, A.; Gomis-Bellmunt, O. Participation of wind power plants in system frequency control: Review of grid code requirements and control methods. Renew. Sustain. Energy Rev. 2014, 34, 551-564. [CrossRef]

43. Dreidy, M.; Mokhlis, H.; Mekhilef, S. Inertia response and frequency control techniques for renewable energy sources: A review. Renew. Sustain. Energy Rev. 2017, 69, 144-155. [CrossRef]

44. Ekanayake, J.; Jenkins, N. Comparison of the response of doubly fed and fixed-speed induction generator wind turbines to changes in network frequency. IEEE Trans. Energy Convers. 2004, 19, 800-802. [CrossRef]

45. Gonzalez-Longatt, F.; Chikuni, E.; Stemmet, W.; Folly, K. Effects of the synthetic inertia from wind power on the total system inertia after a frequency disturbance. In Proceedings of the Power Engineering Society Conference and Exposition in Africa, Johannesburg, South Africa, 9-13 July 2012; pp. 9-13.

46. Bonfiglio, A.; Invernizzi, M.; Labella, A.; Procopio, R. Design and Implementation of a Variable Synthetic Inertia Controller for Wind Turbine Generators. IEEE Trans. Power Syst. 2018, 34, 754-764. [CrossRef]

47. Singarao, V.Y.; Rao, V.; Harral, M.A. Review on engineering and regulatory aspects associated with frequency control capabilities of wind power plants. In Proceedings of the 2013 IEEE Energytech, Cleveland, OH, USA, 21-23 May 2013; pp. 1-6.

48. Tarnowski, G.C.; Kjar, P.C.; Sorensen, P.E.; Ostergaard, J. Variable speed wind turbines capability for temporary over-production. In Proceedings of the Power \& Energy Society General Meeting, Calgary, AB, Canada, 26-30 July 2009; pp. 1-7. 
49. Keung, P.K.; Li, P.; Banakar, H.; Ooi, B.T. Kinetic energy of wind-turbine generators for system frequency support. IEEE Trans. Power Syst. 2009, 24, 279-287. [CrossRef]

50. El Itani, S.; Annakkage, U.D.; Joos, G. Short-term frequency support utilizing inertial response of DFIG wind turbines. In Proceedings of the Power and Energy Society General Meeting, Detroit, MI, USA, 24-28 July 2011; pp. 1-8.

51. Hafiz, F.; Abdennour, A. Optimal use of kinetic energy for the inertial support from variable speed wind turbines. Renew. Energy 2015, 80, 629-643. [CrossRef]

52. Kang, M.; Kim, K.; Muljadi, E.; Park, J.W.; Kang, Y.C. Frequency control support of a doubly-fed induction generator based on the torque limit. IEEE Trans. Power Syst. 2016, 31, 4575-4583. [CrossRef]

53. Fernández-Guillamón, A.; Villena-Lapaz, J.; Vigueras-Rodríguez, A.; García-Sánchez, T.; Molina-García, Á. An Adaptive Frequency Strategy for Variable Speed Wind Turbines: Application to High Wind Integration Into Power Systems. Energies 2018, 11, 1436. [CrossRef]

54. Liu, K.; Qu, Y.; Kim, H.M.; Song, H. Avoiding Frequency Second Dip in Power Unreserved Control During Wind Power Rotational Speed Recovery. IEEE Trans. Power Syst. 2018, 33, 3097-3106. [CrossRef]

55. Staino, A.; Basu, B. Dynamics and control of vibrations in wind turbines with variable rotor speed. Eng. Struct. 2013, 56, 58-67. [CrossRef]

56. Rahman, M.; Ong, Z.C.; Chong, W.T.; Julai, S.; Khoo, S.Y. Performance enhancement of wind turbine systems with vibration control: A review. Renew. Sustain. Energy Rev. 2015, 51, 43-54. [CrossRef]

57. Hansen, A.D.; Altin, M.; Margaris, I.D.; Iov, F.; Tarnowski, G.C. Analysis of the short-term overproduction capability of variable speed wind turbines. Renew. Energy 2014, 68, 326-336. [CrossRef]

58. Lind, P.G.; Herráez, I.; Wächter, M.; Peinke, J. Fatigue load estimation through a simple stochastic model. Energies 2014, 7, 8279-8293. [CrossRef]

59. Fernández-Guillamón, A.; Sarasúa, J.I.; Chazarra, M.; Vigueras-Rodríguez, A.; Fernández-Muñoz, D.; Molina-García, Á. Frequency control analysis based on unit commitment schemes with high wind power integration: A Spanish isolated power system case study. Int. J. Electr. Power Energy Syst. 2020, 121, 106044. [CrossRef]

60. Padrón, S.; Hernández, M.; Falcón, A. Reducing under-frequency load shedding in isolated power systems using neural networks. Gran Canaria: A case study. IEEE Trans. Power Syst. 2015, 31, 63-71. [CrossRef]

61. Martínez-Lucas, G.; Sarasúa, J.I.; Sánchez-Fernández, J.Á. Frequency regulation of a hybrid wind-hydro power plant in an isolated power system. Energies 2018, 11, 239. [CrossRef]

62. Aziz, A.; Oo, A.T.; Stojcevski, A. Frequency regulation capabilities in wind power plant. Sustain. Energy Technol. Assess. 2018, 26, 47-76. [CrossRef]

63. Mansoor, S.; Jones, D.; Bradley, D.A.; Aris, F.; Jones, G. Reproducing oscillatory behaviour of a hydroelectric power station by computer simulation. Control Eng. Pract. 2000, 8, 1261-1272. [CrossRef]

64. Sarasúa, J.I.; Martínez-Lucas, G.; Lafoz, M. Analysis of alternative frequency control schemes for increasing renewable energy penetration in El Hierro Island power system. Int. J. Electr. Power Energy Syst. 2019, 113, 807-823. [CrossRef]

65. Kundur, P.; Balu, N.J.; Lauby, M.G. Power System Stability and Control; McGraw-Hill: New York, NY, USA, 1994; Volume 7.

66. Pöller, M.; Achilles, S. Aggregated wind park models for analyzing power system dynamics. In Proceedings of the 4th International Workshop on Large-Scale Integration of Wind Power and Transmission Networks for Offshore Wind Farms, Billund, Denmark, 20-21 October 2003.

67. Clark, K.; Miller, N.W.; Sanchez-Gasca, J.J. Modeling of GE wind turbine-generators for grid studies. GE Energy 2010, 4, 0885-8950.

68. Zhao, S.; Nair, N.K. Assessment of wind farm models from a transmission system operator perspective using field measurements. IET Renew. Power Gener. 2011, 5, 455-464. [CrossRef]

69. Martínez-Lucas, G.; Sarasúa, J.I.; Sánchez-Fernández, J.Á. Eigen analysis of wind-hydro joint frequency regulation in an isolated power system. Int. J. Electr. Power Energy Syst. 2018, 103, 511-524. [CrossRef]

70. Perez-Diaz, J.I.; Sarasua, J.I.; Wilhelmi, J.R. Contribution of a hydraulic short-circuit pumped-storage power plant to the load-frequency regulation of an isolated power system. Int. J. Electr. Power Energy Syst. 2014, 62, 199-211. [CrossRef] 
71. UCTE (Union for the Co-ordination of Transmission of Electricity). Operation Handbook. 2004. Available online: https:/ / www.entsoe.eu/publications/system-operations-reports/operation-handbook (accessed on 4 May 2020).

72. Wood, A.J.; Wollenberg, B.F.; Sheblé, G.B. Power Generation, Operation, and Control; John Wiley \& Sons: Hoboken, NJ, USA, 2013.

73. Sigrist, L. A UFLS scheme for small isolated power systems using rate-of-change of frequency. IEEE Trans. Power Syst. 2014, 30, 2192-2193. [CrossRef]

74. Dai, Y.; Xu, Y.; Dong, Z.; Wong, K.; Zhuang, L. Real-time prediction of event-driven load shedding for frequency stability enhancement of power systems. IET Gener. Transm. Distrib. 2012, 6, 914-921. [CrossRef]

75. Arani, M.F.M.; Mohamed, Y.A.R.I. Analysis and mitigation of undesirable impacts of implementing frequency support controllers in wind power generation. IEEE Trans. Energy Convers. 2015, 31, 174-186. [CrossRef]

(c) (

(C) 2020 by the authors. Licensee MDPI, Basel, Switzerland. This article is an open access article distributed under the terms and conditions of the Creative Commons Attribution (CC BY) license (http:/ / creativecommons.org/licenses/by/4.0/). 